\title{
Response surface method applied to optimization of estradiol permeation in chitosan membranes
}

\author{
LUCIANO MENGATTO*, MARÍA I CABRERA ${ }^{\dagger}$ and JULIO A LUNA \\ Laboratorio de Química Fina, INTEC - UNL - CONICET, Centro Científico Tecnológico, \\ Ruta Nacional 168 Paraje El Pozo, Santa Fe, Argentina
}

MS received 27 June 2011; revised 24 August 2011

\begin{abstract}
The present work deals with the study of estradiol permeation in chitosan membranes. A fractional factorial design was built for the determination of the main factors affecting estradiol permeation. The independent factors analysed were: concentration of chitosan, concentration of cross-linking agent, cross-linking time and thermal treatment. It was found that concentration of chitosan and cross-linking time significantly affected the response. The effects of thermal treatment and concentration of cross-linking agent were not significant. An optimization process based on response surface methodology was carried out in order to develop a statistical model which describes the relationship between active independent variables and estradiol flux. This model can be used to find out a combination of factor levels during response optimization. Possible options for response optimization are to maximize, minimize or move towards a target value.
\end{abstract}

Keywords. Chitosan; dry heat; mass transport; membranes; water sorption.

\section{Introduction}

Chitosan (CHT) is an abundant, low cost, biodegradable, biocompatible and non-toxic polysaccharide with good membrane and gel forming properties. Membranes have found applications in drug delivery systems, skin permeation simulation, waste water treatment, packaging in food industry and textile dyeing (Ravi Kumar 2000; Stamatialis et al 2008).

CHT membranes prepared by a casting solvent evaporation technique can be obtained at ambient or higher temperature. A higher temperature reduces time needed for solvent evaporation. Thermal treatment of freshly formed membranes can be an alternative method of altering the structure, decreasing solubility and increasing the strength. Various processes including amidation, degradation and cross-linking of polymeric chains take place during thermal treatment (Zotkin et al 2004). Lim and Wan (1995) reported that heat treatment decreased the extent of swelling and dissolution of CHT films in aqueous media. Retuert et al (2000) suggested that films hardness increases with a moderate heating $\left(60 \cdot 0^{\circ} \mathrm{C}\right)$ after $1 \mathrm{~h}$. Ritthidej et al (2002) evaluated physicochemical change of films after moist heat treatment and concluded that water sorption and dissolution of the films were decreased after treatment. Bernabé et al (2005) studied the effect of thermal cross-linking on swelling behaviour of $\mathrm{CHT} /$ pectin polyelectrolyte complex membranes. The thermally treated membranes were stable in strong acid and basic media and swelling decreased as the time of thermal

\footnotetext{
*Author for correspondence (lmengatto@ santafe-conicet.gov.ar)

${ }^{\dagger}$ Since deceased
}

treatment increased. Moreover, the effect of heat treatment was studied on other polymers than CHT. Pongjanyakul et al (2006) studied the effect of heat treatment $\left(65^{\circ} \mathrm{C}\right)$ on drug release from glyceryl palmitostearate-alginate beads.

CHT membrane properties can also be modified by crosslinking reactions. Cross-linking is a process where polymeric chains are linked either by covalent bonds or by physical interactions between the polymer and the cross-linking agent or between the polymers themselves. A cross-linking reaction can increase chemical stability and stiffness, alter permeability, absorption capacity and colour (Neto et al 2005). According to Berger et al (2004), cross-linking density is defined as the ratio of moles of cross-linking agent to the moles of polymer repeating units. The cross-linking agent tripolyphosphate can possess a high charge density and it is able to diffuse into CHT membranes. Its use as ionic crosslinking agent has been extensively reported (Shu and Zhu 2002; Mengatto et al 2010).

Experimental design and optimization are tools that are used to systematically examine different types of problems that arise within research, development and production. A screening experiment is performed in order to determine the experimental variables and interactions that have significant influence on the response. The goal in any optimization is to find out the conditions that produce the desired response. Statistical methods, including response surface methodology and artificial neural networks, are used in developing and optimizing polymeric systems for a wide range of applications (Dureja et al 2001; Rana et al 2004, 2005; Leonardi et al 2008; Khayet et al 2010). Estradiol (E2) is a female hormone. Whether as hormonal 
contraception throughout the reproductive years or as hormone therapy at menopause, E2 is widely used. This hormone is also a contaminant present in waste water effluent.

Membrane technology involves the knowledge about polymer membranes and drug relationships. Essentially, based on permeation aspects, molecules can diffuse through the polymer or through water-filled pores. Interactions between the molecules to be diffused and the polymer, such as hydrogen bonds, should be considered (Banasiak and Schäfer 2010). Moreover, dissolution, erosion and water sorption or swelling can contribute to the permeation process. Several hormones were studied in applications concerning membranes. Controlled release systems where human growth hormone was incorporated into a polymer matrix (Fredenberg et al 2011) and ethinylestradiol was included into a reservoir placed between a drug impermeable layer and a membrane were developed (Gao et al 2009). The purification and separation of insulin is an important step in pharmaceutical industry. Planned membrane design leads to the preparation of membranes which are promising filter candidates for size-exclusion separation (Akbache et al 2009; El-Safty and Shenashena 2011). The retention of micropollutants such as estrone from water is an important issue with regard to wastewater treatment and involves membrane filtration technology (Schäfer et al 2010). Nghiem et al (2004) investigated recycling of domestic waste water effluent using thinfilm composite nanofiltration membranes for the removal of E2 and its metabolite estrone. They concluded that the transport mechanism of E2 through the membrane is diffusion rather than convection; however, the role of water in facilitating this transport remains unclear. Braeken et al (2005) reported that E2 retention in nanofiltration was lower than expected, based on the molecular weight cut-off of membranes. The interaction between E2 and CHT was studied in a previous work (Mengatto et al 2010). The results suggested that the existence of pore filled water inside the polymeric membrane may contribute to E2 diffusion because of its hydrophobicity and less solvation. As noted, some of the uses of CHT membranes are waste water treatment and the development of drug delivery systems. For these reasons it is important to increase knowledge on the E2 flux through CHT cross-linked membranes focusing on the development of a model which describes the relationship between membrane formulation variables and E2 flux.

The aim of this study was to determine the influence of four preparation parameters of CHT membranes on E2 flux, and then develop a statistical model which could be used to find out the experimental combinations of factors to prepare membranes for different potential applications.

\section{Experimental}

\subsection{Material}

CHT was purchased from Polymar (Brazil). Sodium tripolyphosphate (TPP) and E2 (purity 99\%) were purchased from Sigma (US). Acetonitrile was HPLC grade (Merck,
Germany). Acetic acid and ethanol were both PA $>99.5 \%$ (Cicarelli, Argentina). Isotonic phosphate buffer saline (PBS, $\mathrm{pH} 7.4$ ) was prepared by dissolving $8 \mathrm{~g}$ of $\mathrm{NaCl}, 0.2 \mathrm{~g}$ of $\mathrm{KCl}, 0.2 \mathrm{~g}$ of $\mathrm{KH}_{2} \mathrm{PO}_{4}$ and $1.44 \mathrm{~g}$ of $\mathrm{Na}_{2} \mathrm{HPO}_{4} \cdot 2 \mathrm{H}_{2} \mathrm{O}$ in 11 of water. Sodium chloride, potassium chloride, potassium phosphate monobasic, sodium phosphate dibasic dehydrate and sodium acetate (Anedra, Argentina) were of analytical grade.

Experimental design and data analysis were performed with software Stat-Ease Design-Expert trial Version 7.0. Results were considered statistically significant if $p<0 \cdot 05$.

\subsection{Characterization of chitosan powder}

The degree of deacetylation (DD) was determined from elemental analysis. Carbon $(\% \mathrm{C})$, hydrogen $(\% \mathrm{H})$ and nitrogen $(\% \mathrm{~N})$ contents in CHT samples were measured on an Exeter CE 440 elemental analyser. The DD was calculated from nitrogen-carbon ratio according to (1) reported by Dong et al (2001)

$$
\frac{\% \mathrm{~N}}{\% \mathrm{C}}=\frac{14}{96-24 \mathrm{DD}}
$$

The weight average molecular weight $\left(\bar{M}_{\mathrm{w}}\right)$ was determined from static light scattering measurement. A multi angle laser light scattering photometer from Brookhaven Instruments was used. CHT solutions were prepared in $0.2 \mathrm{M}$ acetic acid/ $0 \cdot 1 \mathrm{M}$ sodium acetate aqueous solution and filtered through glass filter and membrane filter of $0.2 \mu \mathrm{m}$. The experiments were carried out over an angular range from $30^{\circ}$ to $150^{\circ}$ at $632.8 \mathrm{~nm}$ and ambient temperature. Data were analysed by the Zimm plot method (Wang et al 1991).

\subsection{Quantification of estradiol by HPLC - Evaluation of the method performance}

The HPLC instrumentation (Shimadzu model LC-10) consisted of a ternary team of high-performance liquid chromatography with UV detection by diode array. The chromatographic system and conditions of analysis were performed, assembling US Pharmacopoeia recommendations for E2 (USP 2007), as follows: C18 column (Spherisorb ODS2, $250 \times 4.6 \mathrm{~mm}, 5 \mathrm{~mm}$ internal diameter), mobile phase acetonitrile:water (50:50), flow rate $1 \mathrm{ml} \mathrm{min}^{-1}$, oven temperature $30^{\circ} \mathrm{C}$, wavelength $280 \mathrm{~nm}$, stop time $8 \mathrm{~min}$ and injection manual volume $20 \mu$ l.

E2 was dissolved in ethanol $\left(300 \mu \mathrm{g} \mathrm{ml}^{-1}\right)$ and stored $\left(4^{\circ} \mathrm{C}\right)$ in darkness condition as stock solution. The standard solutions for the evaluation of the analytical method performance were prepared by dilution of an exact volume of the stock solution in ethanol:PBS (40:60). The standard solutions were filtered through a membrane filter of $0.45 \mu \mathrm{m}$.

In order to verify the linearity of the analytical procedure within a concentration range of $0.5-100 \mu \mathrm{g} \mathrm{ml}^{-1}$ of E2, seven concentration levels were prepared and analysed three times each. The calibration curve (peak area vs E2 concentration) was fitted to a straight line, using linear 
regression analysis. The precision of the procedure expressed as the coefficient of variation $(\mathrm{CV} \%)$ was determined by the analysis within same day of six replicates of three standard solutions at three levels of concentration $(3 \cdot 0,10 \cdot 0$ and $50.0 \mu \mathrm{g} \mathrm{ml}^{-1}$ ). Intermediate precision (CV\%) was also determined to evaluate variations between different days. Six replicates of $25.0 \mu \mathrm{g} \mathrm{ml}^{-1}$ of E2 concentration were analysed on three different days (ICH 2005).

\subsection{Preparation of cross-linked chitosan membranes}

CHT membranes were obtained by a casting solvent evaporation technique. Polymer solutions ( 3 and $4 \% \mathrm{w} / \mathrm{v}$ ) were prepared by dissolving CHT in a $2 \mathrm{M}$ acetic acid solution. A portion was poured on a polycarbonate Petri dish and subjected to drying at room temperature until constant weight. The dried membranes were stored in polyethylene bags till use, but for a maximum of 7 days. Bags were kept in a closed container under darkness condition. Circular sections of the dried membranes $\left(5 \mathrm{~cm}^{2}\right)$ were cut and subjected to dry thermal treatment $\left(60^{\circ} \mathrm{C}-60 \mathrm{~min}\right)$. Subsequently, they were cross-linked by dipping in a TPP solution $(10 \mathrm{ml}-5 \% \mathrm{w} / \mathrm{v})$ for $15 \mathrm{~min}$ and introduced into bottles having $10 \mathrm{ml}$ of ethanol:PBS solution (40:60). At predetermined times the membranes were taken out; excess water was removed carefully with filter paper from the membrane surface, and then weighed immediately. This procedure was repeated until the membranes reached constant weight. Equilibrium water content (EWC) and swelling ratio (SR) were calculated according to the following equations (Shu and Zhu 2002; El-Sherbiny and Smyth 2010), respectively:

$$
\begin{aligned}
& E W C\left(\mathrm{~g} \mathrm{~g}^{-1}\right)=\frac{W_{\mathrm{s}}-W_{0}}{W_{\mathrm{s}}}, \\
& S R=\frac{W_{\mathrm{s}}}{W_{0}},
\end{aligned}
$$

where $W_{0}$ is the initial dry weight and $W_{\mathrm{s}}$ the swollen equilibrium weight.

The same cross-linking and EWC evaluation procedures were performed for membranes without thermal treatment. The thickness of cross-linked membranes with and without thermal treatment was determined with a micrometer. The thickness was measured in five places of the circular sections.

\subsection{In vitro diffusion experiments}

In order to determine the main factor affecting E2 flux, a fractional factorial design $\left(2^{4-1}\right)$ at two levels was built. The independent factors analysed were: concentration of CHT ( 3 and $4 \% \mathrm{w} / \mathrm{v}$ ), concentration of cross-linking agent ( 5 and $10 \% \mathrm{w} / \mathrm{v})$, cross-linking time (15 and $45 \mathrm{~min}$ ) and thermal treatment (with or without exposure to $60^{\circ} \mathrm{C}-60 \mathrm{~min}$ ). The factors showing significant effects were then considered for a central composite design (CCD) consisting of 12 experiments in order to develop a statistical model. All CHT membranes were prepared following the methodology reported in $\S 2.4$.

Diffusion experiments were conducted using a vertical Franz diffusion cell (Permegear Inc. US). The receptor fluid was thermostatically regulated to $37^{\circ} \mathrm{C}$ under moderate stirring. Firstly, a freshly cross-linked membrane was clamped between donor and receptor compartments. The membrane was allowed to equilibrate overnight with diffusion medium. The donor fluid was exchanged with a fresh donor solution containing E2 $\left(500 \mu \mathrm{g} \mathrm{ml}^{-1}\right)$ in 40:60 ethanol:PBS mixture. Aliquots $(200 \mu \mathrm{l})$ were withdrawn from the receptor compartment and assayed by HPLC. An equal volume of fresh medium was added to maintain a constant volume.

E2 flux was calculated from the slope of the linear portion of the cumulative amount permeated per unit area vs time plots.

\subsection{Morphology observation}

The surface and cross-section morphology of cross-linked membranes were observed. Cross-section samples were prepared by fracturing cross-linked membranes after immersion in liquid nitrogen. Several samples were mounted on metal grids and coated with gold using a Sputter/Carbon coating system (SPI Supplies). Coated samples were observed using a JEOL JSM-35C scanning electron microscope.

\section{Results and discussion}

The functional, physical and chemical properties of CHT depend on its molecular weight and DD. Therefore, the determination of these parameters should be one of the routine analyses performed when CHT is used. The DD determined from elemental analysis was $73.0 \%$ and the $\bar{M}_{\mathrm{w}}$ determined from static light scattering measurement was $285 \mathrm{kDa}$.

Before permeation study, an analytical method for drug quantification should be developed and evaluated. The evaluation of performance of the method showed that the model can explain $\sim 99.98 \%\left(R^{2}\right)$ of the variation in the response variable. The corresponding correlation coefficient $(R)$ was 0.9999 and indicated a large relationship between the variables. The $p$-value of the model was smaller than 0.05 $(p=0.0000)$ and indicated a statistically significant relationship between peak area and E2 concentration for a significance level of $95.0 \%$. The $p$-value of the lack-of-fit was higher than 0.05 ( $p=0.6011)$ and indicated that the proposed lineal model fitted well for a significance level of $95.0 \%$. The precision of the procedure was determined by the analysis within same day of six replicates of three standard solutions at three levels of concentration. $\mathrm{CV}$ values were smaller than $2.0 \%$ and indicated good precision. CV values for each level of concentration were $1.87 \%\left(3.0 \mu \mathrm{g} \mathrm{ml}^{-1}\right)$, $1.71 \%\left(10.0 \mu \mathrm{g} \mathrm{ml}^{-1}\right)$ and $0.81 \%\left(50.0 \mu \mathrm{g} \mathrm{ml}^{-1}\right)$. Intermediate precision was also good $(\mathrm{CV}=2 \cdot 92 \%)$. Good results obtained with respect to linearity and precision indicated that the analytical procedure can be used to quantify E2. 
All the cross-linked membranes retained their flexibility and integrity in the ethanol:PBS mixture and were translucent.

Table 1 shows swelling experimental results. Thermal treatment significantly decreased weight after cross-linking, EWC and SR in comparison with non-exposed membranes $(p<0.05)$. This result agrees with that reported by Bernabé et al (2005). Water loss and more close interactions between polymeric chains are proposed as explanation. However, thermal treatment had no effect on the thickness after crosslinking $(p>0.05)$. According to this result, thermal treatment was included in statistical screening to evaluate its effect on E2 permeation.

To find out the main factors affecting E2 flux, a two-level fractional factorial design was built. Table 2 shows independent factor combinations and response values. The analysis of variance (ANOVA) showed that model ( $p=0.0003)$, concentration of CHT $(p=0.0001)$ and cross-linking time $(p=$ 0.0002) were significant. Effects were considered statistically significant due to $p$-value which was smaller than 0.05 . The response decreased as the concentration of polymer increased. E2 flux increased with an increase in cross-linking time. The effects of concentration of cross-linking agent $(p=0.3277)$ and thermal treatment $(p=0.9031)$ were not significant. It has been proposed that drug diffusion may decrease, with more cross-linked sites formed due to prolongation of cross-linking time or increase in concentration of cross-linking agent (Berger et al 2004). In this work, E2 flux increased with an increase in cross-linking time and an increase in concentration of cross-linking agent, although the effect of the second was not significant. These results were in agreement with Rana et al $(2004,2005)$ who reported an increase in the flux of 5-fluorouracil and indomethacin with an increase in concentration of cross-linking agent. For the system under study, the relation between E2 hydrophobicity and CHT hydrophilicity was proposed as explanation (Mengatto et al 2010). Figure 1 shows normal probability plot and Pareto chart. The normal plot probability indicates whether the residuals follow a normal distribution. Significant effects show up as deviations from the straight line. Concentration of CHT and cross-linking time deviated from normality. Similar conclusions were achieved with the Pareto chart. Effects of concentration of CHT and crosslinking time were above the Bonferroni limit and were almost certainly significant. Although thermal treatment decreased EWC (table 1), the effect was not significant. Temperature and duration of heat treatment determine the degree of heat induced changes. More drastic treatment conditions could result in a significant effect on drug flux. Three replicates of two membranes randomly selected from fractional factorial design were analysed. CV values obtained for E2 flux evaluated at steady state were lower than $10 \%$ and indicated good reproducibility (Chilcott et al 2005). Figure 2 shows amount of E2 diffused through CHT membranes as a function of time. Over a time, the flux approached a steady-state value and the cumulative amount penetrating the membrane increased linearly in time. However, time (lag time) was

Table 1. Swelling experimental results.

\begin{tabular}{|c|c|c|c|c|}
\hline & \multicolumn{2}{|c|}{ CHT 3 (\% w/v) } & \multicolumn{2}{|c|}{ CHT 4 (\% w/v) } \\
\hline & Without TT & With TT & Without TT & With TT \\
\hline Weight after CL (g) & $0 \cdot 1661(0 \cdot 0002)$ & $0 \cdot 1474(0 \cdot 0006)$ & $0 \cdot 2852(0 \cdot 0009)$ & $0 \cdot 2449(0 \cdot 0003)$ \\
\hline Thickness after CL $(\mu \mathrm{m})$ & $217(6)$ & $213(6)$ & $323(7)$ & $327(6)$ \\
\hline $\operatorname{EWC}\left(\mathrm{g} \mathrm{g}^{-1}\right)$ & $0 \cdot 286(0 \cdot 005)$ & $0.274(0.005)$ & $0 \cdot 316(0 \cdot 004)$ & $0 \cdot 302(0 \cdot 003)$ \\
\hline SR & $1.401(0.0013)$ & $1 \cdot 372(0 \cdot 007)$ & $1 \cdot 462(0 \cdot 010)$ & $1.434(0.007)$ \\
\hline
\end{tabular}

CHT: chitosan, TT: thermal treatment, CL: cross-linking, EWC: equilibrium water content, SR: swelling ratio, SD in parentheses $(n \geq 3)$.

Table 2. Fractional factorial design used in study of variables affecting E2 flux.

\begin{tabular}{|c|c|c|c|c|c|}
\hline \multirow[b]{2}{*}{ Experiment } & \multicolumn{4}{|c|}{ Factors } & \multirow{2}{*}{ 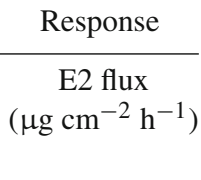 } \\
\hline & $\begin{array}{c}\text { Concentration of } \\
\text { CHT } \\
(\% \mathrm{w} / \mathrm{v})\end{array}$ & $\begin{array}{c}\text { Concentration of } \\
\text { TPP } \\
(\% \mathrm{w} / \mathrm{v})\end{array}$ & $\begin{array}{c}\text { Cross-linking } \\
\text { time } \\
\text { (min) }\end{array}$ & $\begin{array}{l}\text { Thermal } \\
\text { treatment }\end{array}$ & \\
\hline 1 & 3 & 10 & 15 & With & $5 \cdot 8625$ \\
\hline 2 & 4 & 5 & 15 & With & $2 \cdot 3700$ \\
\hline 3 & 4 & 5 & 45 & Without & $4 \cdot 8743$ \\
\hline 4 & 4 & 10 & 45 & With & $5 \cdot 2806$ \\
\hline 5 & 3 & 10 & 45 & Without & $13 \cdot 2250$ \\
\hline 6 & 3 & 5 & 15 & Without & $5 \cdot 8000$ \\
\hline 7 & 4 & 10 & 15 & Without & 2.5538 \\
\hline 8 & 3 & 5 & 45 & With & $13 \cdot 2570$ \\
\hline
\end{tabular}

CHT: chitosan, TPP: sodium tripolyphosphate, E2: estradiol. 


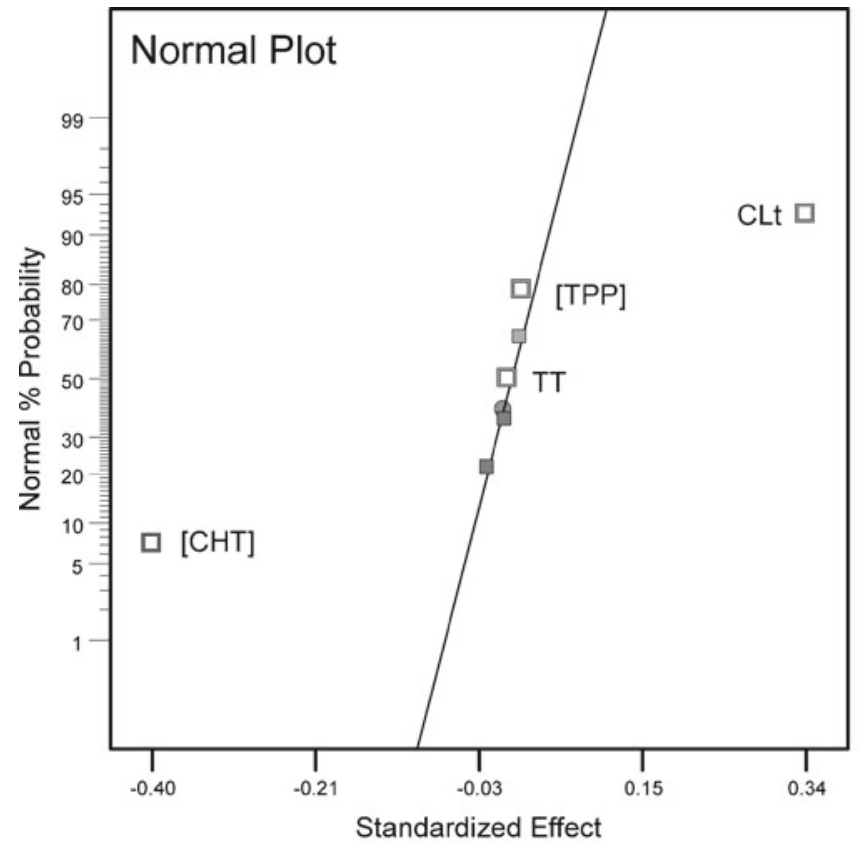

[CHT]: Concentration of chitosan

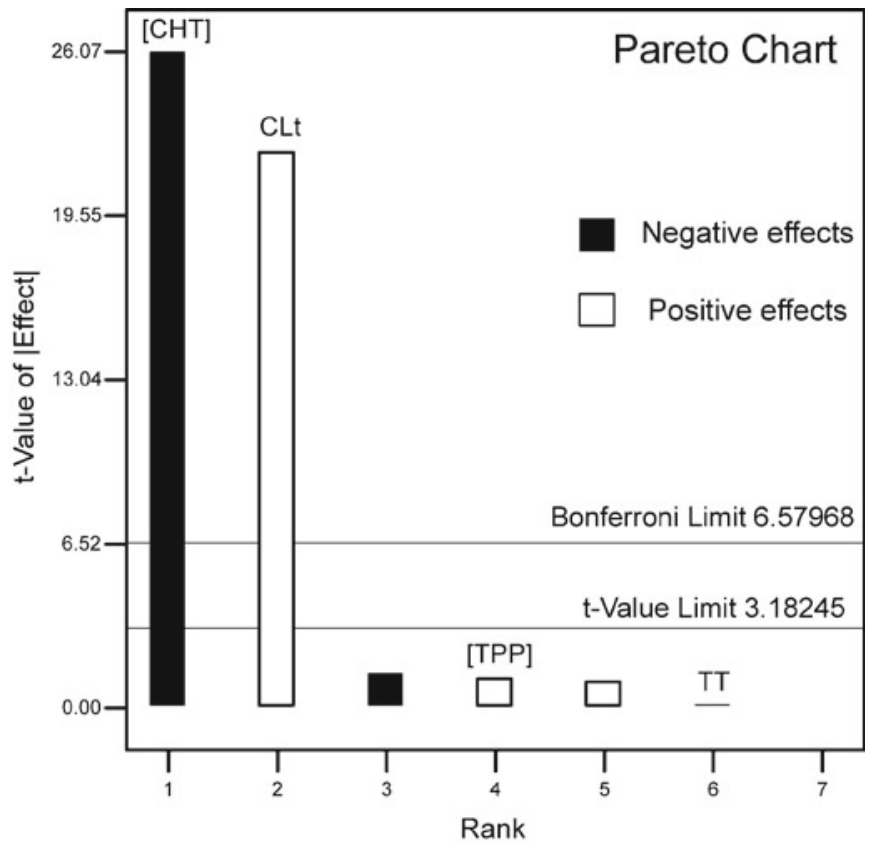

CLt: Cross-linking time TT: Thermal treatment

Figure 1. Normal probability plot and Pareto chart.

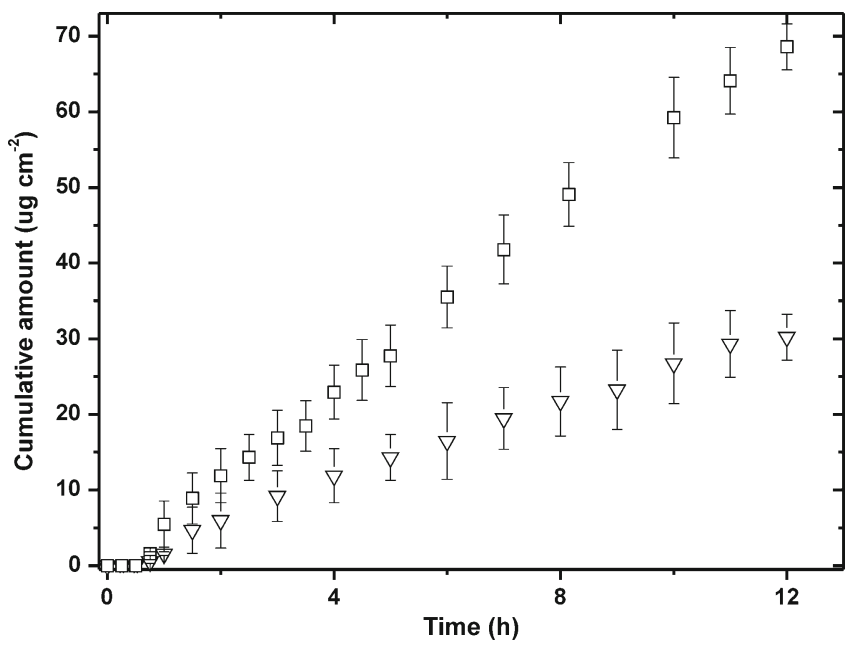

Figure 2. Cumulative amount permeated per unit area vs time plots. Membranes were prepared according to factors combination of experience number 1 (square) and number 7 (triangle) of fractional factorial design.

required after initial contact with membranes for such a steady state to be achieved.

Table 3 shows independent factor combinations and response values of CCD. Due to the fact that the effect of concentration of cross-linking agent was not significant, for membrane preparation, low level of this factor was selected. Then, membranes were cross-linked by dipping in a $5 \% \mathrm{w} / \mathrm{v}$ TPP solution. A lineal model was proposed and the model coefficients were validated by ANOVA. The $p$-value of the model was smaller than $0.05(p=0.0046)$ and indicated that
Table 3. Central composite design.

\begin{tabular}{|c|c|c|c|}
\hline Experiment & $\begin{array}{c}\text { Concentration } \\
\text { of CHT }(\% \mathrm{w} / \mathrm{v})\end{array}$ & $\begin{array}{l}\text { Cross-linking } \\
\text { time }(\min )\end{array}$ & $\begin{array}{c}\text { E2 flux } \\
\left(\mu \mathrm{g} \mathrm{cm}^{-2} \mathrm{~h}^{-1}\right)\end{array}$ \\
\hline 1 & $3 \cdot 50$ & $30 \cdot 00$ & $7 \cdot 7658$ \\
\hline 2 & $4 \cdot 34$ & $30 \cdot 00$ & $2 \cdot 4571$ \\
\hline 3 & $2 \cdot 66$ & $30 \cdot 00$ & $15 \cdot 2280$ \\
\hline 4 & $3 \cdot 50$ & $55 \cdot 23$ & $12 \cdot 7430$ \\
\hline 5 & $4 \cdot 00$ & $15 \cdot 00$ & 2.5744 \\
\hline 6 & $3 \cdot 50$ & $30 \cdot 00$ & $5 \cdot 7227$ \\
\hline 7 & $3 \cdot 50$ & $30 \cdot 00$ & $9 \cdot 6351$ \\
\hline 8 & $3 \cdot 50$ & $30 \cdot 00$ & 9.0805 \\
\hline 9 & $3 \cdot 50$ & $4 \cdot 77$ & 9.7409 \\
\hline 10 & $3 \cdot 00$ & $45 \cdot 00$ & $11 \cdot 1690$ \\
\hline 11 & $3 \cdot 00$ & $15 \cdot 00$ & $6 \cdot 4650$ \\
\hline 12 & $4 \cdot 00$ & $45 \cdot 00$ & $4 \cdot 1327$ \\
\hline
\end{tabular}

CHT: chitosan, E2: estradiol.

the model terms were significant. The $p$-value of the lackof-fit was not significant $(p=0.2553>0.05)$ and indicated that the proposed lineal model fitted well for a significance level of $95 \%$. The model can explain $\sim 70.11 \%\left(R^{2}\right)$ of the variation in the response variable and can be used to navigate the design space. The final equation of the statistical model developed is:

$$
\text { E2 flux }=29 \cdot 1728-6 \cdot 7113 \cdot[\text { CHT }]+0 \cdot 079119 \cdot \mathrm{CLt} \text {, }
$$

where $[\mathrm{CHT}]$ is concentration of CHT $(\% \mathrm{w} / \mathrm{v})$ and $\mathrm{CLt}$ is cross-linking time (min). 
This model can be used to find out a combination of factor levels to prepare membranes with definite fluxes. Figure 3 shows a three-dimensional response surface plot of E2 flux,

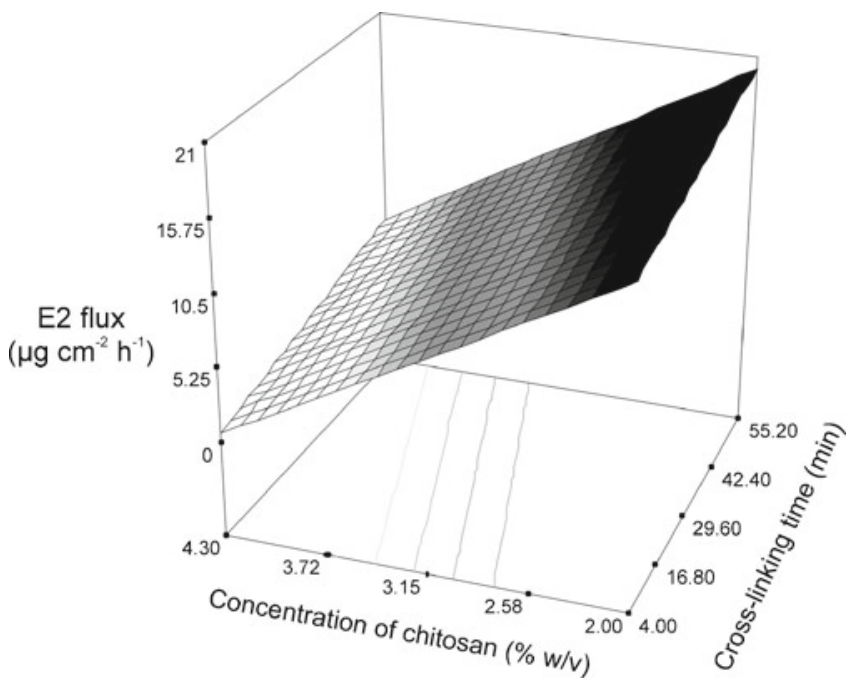

Figure 3. Response surface plot of estradiol (E2) flux. based on the first-order model using concentration of CHT and cross-linking time as independent variables. Because the model is first-order, the fitted response surface is a plane. Based on examination of this fitted surface, it is clear that E2 flux increases as cross-linking time increases and concentration of CHT decreases. Often a fitted surface such as this can be used to determine an appropriate direction of potential improvement for the response.

Figure 4 shows micrographs of the cross-sections (figures $4 \mathrm{a}$ and $\mathrm{b}$ ) and surfaces (figures $4 \mathrm{c}$ and d) of crosslinked membranes. The cross-section micrographs show a dense, compact and homogeneous structure for membranes prepared from concentration of CHT of $2.66 \% \mathrm{w} / \mathrm{v}$ (figure $4 \mathrm{a}$ ) and $3.5 \% \mathrm{w} / \mathrm{v}$ (figure $4 \mathrm{~b}$ ). The surface micrographs show a relatively rough structure for membranes prepared from concentration of CHT of $2.66 \% \mathrm{w} / \mathrm{v}$ (figure $4 \mathrm{c}$ ) and $3.5 \% \mathrm{w} / \mathrm{v}$ (figure $4 \mathrm{~d}$ ). These membranes were prepared with $5 \% \mathrm{w} / \mathrm{v}$ concentration of cross-linking agent and $30 \mathrm{~min}$ of cross-linking time (according to CCD). As the membranes prepared in this work were dense rather than porous, additional information could not be obtained from morphological observation.
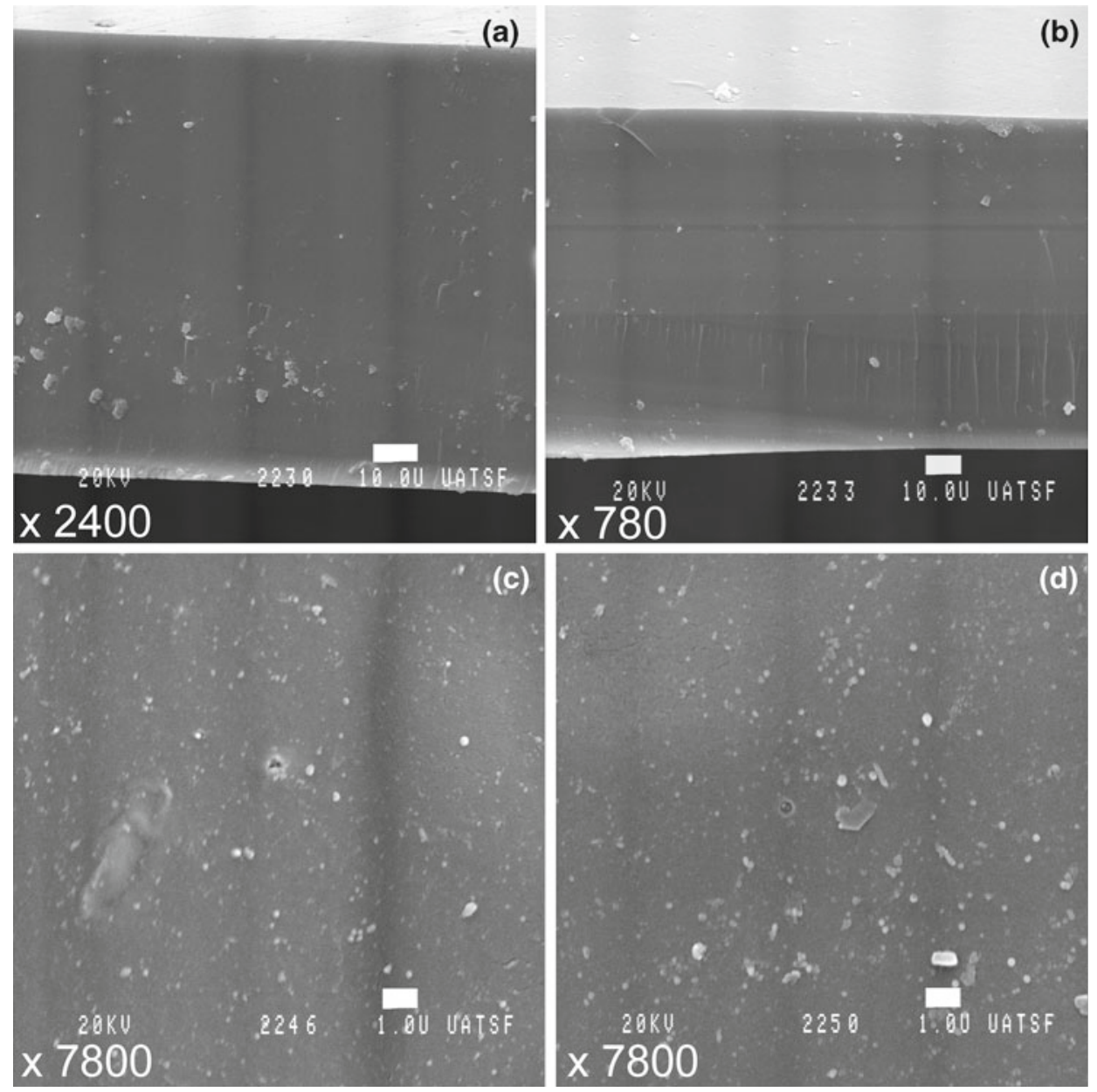

Figure 4. Morphology of cross-sections (a and $\mathbf{b}$ ) and surfaces (c and $\mathbf{d}$ ) of cross-linked membranes prepared from a concentration of chitosan of $2.66 \% \mathrm{w} / \mathrm{v}(\mathbf{a}$ and $\mathbf{c})$ and $3.5 \% \mathrm{w} / \mathrm{v}(\mathbf{b}$ and $\mathbf{d}$ ). 
In the current work, concentration of CHT, concentration of cross-linking agent and cross-linking time were selected for fractional factorial design based on its significant effects on drug permeation in CHT membranes (Dureja et al 2001; Rana et al 2004, 2005; Mengatto et al 2010). Moreover, thermal treatment was included in an experimental design for the first time. However, the effects of concentration of cross-linking agent and thermal treatment were not significant for the system under study (CHT-E2). These results contribute to demonstrate the importance of screening phase looking for active variables on the response under study in any experimental procedure.

\section{Conclusions}

The data presented in this work concern the study of effect of CHT membrane formulation factors on E2 flux. It was found that concentration of CHT and cross-linking time significantly affected E2 flux. The effects of concentration of cross-linking agent and thermal treatment were not significant. The statistical model developed from CCD could be used to prepare CHT membranes with specific E2 flux. For example, these membranes with specific E2 flux could have great potential application in the recycling of waste water effluents for the removal of E2 (a current contaminant) or in the pharmaceutical industry for the development of delivery systems.

\section{Acknowledgements}

The authors thank CONICET (Consejo Nacional de Investigaciones Científicas y Técnicas) and LIF SE (Laboratorio Industrial Farmacéutico SE-Provincia de Santa Fe) for financial support.

\section{References}

Akbache A, Lamiot E, Moroni O, Turgeon S, Gauthier S and Pouliot Y 2009 J. Membr. Sci. 326435

Banasiak L and Schäfer A 2010 J. Membr. Sci. 365198

Berger J, Reist M, Mayer JM, Felt O, Peppas NA and Gurny R 2004 Eur. J. Pharm. Biopharm. 5719
Bernabé P, Peniche C and Argüelles-Monal W 2005 Polym. Bull. 55 367

Braeken L, Ramaekers R, Zhang Y, Maes G, Van der Bruggen B and Vandecasteele C 2005 J. Membr. Sci. 252195

Chilcott R P et al 2005 J. Pharm. Sci. 94632

Dong Y, Xu C, Wang J, Wu Y, Ruan Y and Wang M 2001 Science in China Serie B $\mathbf{4 4} 216$

Dureja H, Tiwary A K and Gupta S 2001 Int. J. Pharm. 213193

El-Safty S and Shenashena M A 2011 Anal. Chim. Acta 694151

El-Sherbiny I and Smyth H 2010 Carbohydr. Res. 3452004

Fredenberg S, Jönsson M, Laakso T, Wahlgren M, Reslow M and Axelsson A 2011 Int. J. Pharm. 409194

Gao Y, Liang J, Liu J and Xiao Y 2009 Int. J. Pharm. 377128

International Conference on Harmonization of Technical Requirements for Registration of Pharmaceutical for Human use ICH 2005

Khayet M, Abu Seman M H and Hilal N 2010 J. Membr. Sci. 349 113

Leonardi D, Lamas M C and Olivieri A 2008 J. Pharm. Biomed. Anal. 48802

Lim L and Wan L 1995 Drug Dev. Ind. Pharm. 21839

Mengatto L, Luna J A and Cabrera M I 2010 J. Mater. Sci. 45 1046

Neto C, Dantas T, Fonseca J and Pereira M 2005 Carbohydr. Res. 3402630

Nghiem L, McCutcheon J, Schäfer A and Elimelech M 2004 Water Sci. Technol. $\mathbf{5 0} 215$

Pongjanyakul T, Sungthongjeen S and Puttipipatkhachorn S 2006 Int. J. Pharm. 31920

Rana V, Babita K, Goyal D and Tiwary A 2004 Acta Pharmacol. 54 287

Rana V, Babita K, Goyal D and Tiwary A 2005 J. Pharm. Pharmaceut. Sci. 810

Ravi Kumar M 2000 React. Funct. Polym. 461

Retuert J, Fuentes S, González G and Benavente R 2000 Bol. Soc. Chil. Quim. 45323

Ritthidej G, Phaechamud T and Koizumi T 2002 Int. J. Pharm. 232 11

Schäfer A, Nghiem L, Meier A and Neale P 2010 Sep. Purif. Technol. $\mathbf{7 3} 179$

Shu X and Zhu K 2002 Eur. J. Pharm. Biopharm. 54235

Stamatialis D, Papenburg B, Gironés M, Saiful S, Bettahalli S, Schmitmeier S and Wessling M 2008 J. Membr. Sci. 3081

US Pharmacopeial Convention 2007 US Pharmacopeia XXX 285

Wang W, Bo S, Li S and Qin W 1991 Int. J. Biol. Macromol. 13281

Zotkin M, Vikhoreva G, Smotrina T and Derbenev M 2004 Fibre Chem. 3616 